\title{
INFORMATION SYSTEM AS A SERVICE: ISSUES AND CHALLENGES
}

\author{
Muhammad Hilman \\ Faculty of Computer Science, Universitas Indonesia, Kampus Baru UI Depok, 16424 \\ Email: h.hilman@cs.ui.ac.id
}

\begin{abstract}
Information system evolved as the evolution of information technology. The current state of information technology, placed the internet as a main resources of computing. Cloud technology as the backbone of internet has been utilized as a powerful computing resources. Therefore, cloud introduced new term of service oriented technology, popular with "as a service" kind of name. In this paper, the service oriented paradigm will be used to address future trend of information system. Thus, this paper try to introduce the term "information system as a service", holistic view of infrastructure as a service, platform as a service, software as a service, and data as a service
\end{abstract}

Keyword: information system as a service, cloud technology.

\begin{abstract}
Abstrak
Sistem informasi berkembang sebagaimana perkembangan teknologi informasi. State-ofthe-art teknologi informasi, menempatkan internet sebagai sumber utama komputasi. Teknologi cloud sebagai tulang punggung internet, telah dimanfaatkan sebagai sumber daya komputasi yang kuat. Oleh karena itu, teknologi cloud diperkenalkan untuk istilah baru teknologi berorientasi layanan yang populer dengan istilah "as a service". Dalam tulisan ini, paradigma service oriented computing akan digunakan untuk membahas tren sistem informasi di masa depan. Tulisan ini mencoba untuk memperkenalkan istilah "information system as a service", pandangan holistik dari infrastructure as a service, platform as a service, software as a service, dan data as a service.
\end{abstract}

Kata kunci: information system as a service, teknologi cloud.

\section{Introduction}

The era of information system begin with the needs of automated processing in the business routine activity. Basic processing as capturing input of business transaction is the preliminary level of information system supported by computer technology. The time after, level of information system is not only characterized by repeated input capturing processes, it evolved to the development of warehouse technology to store the data captured in the input level. Database technology began to be recognized, thus better storage is needed to make sure that all information stored can be visualized, summarized as readable information. Then, the era of enterprise business level coming. In this level, information system not only takes part as capturing routines activity and storing it to produce the summary, information system has began to give more important part as to support the business top management strategic decision based on information mining and information system intelligence.

The trends of information system are related to the development of information technology. Besides the information system trends, information technology also evolved. Nowadays, internet has taken a big part on information technology paradigm. Begin with the needs of some researcher to share what they have in the computer has made tremendous revolution in the information technology. Internet is not only the tools for sharing information but also have more powerful function. It gives the chance to utilize many resources as of internet is collection of many computer resources. How powerful internet, can be imagined by how much the computers (as a resources) connected each other in the unknown dimension called the cloud. Thus, the cloud can be seen as big asset in information technology. Cloud existence has begun to be utilized as unlimited resources in computing. Many people forecasted 
that cloud as a technology is the future trends of computing era. So, it also can be related to the trend of information system. Information system based on cloud technology or, in the popular term, information system as a service.

Why it has to become "as a service" and what is its relation to the cloud technology? This paper will discuss the future trend of information system related to the development of cloud technology.

\section{Everything as a service}

Papazoglou introduce the term of service oriented computing (SOC). He gives theoretical background and promising research roadmap in the term of SOC. He describes the term SOC as "a new computing paradigm that utilize services as the basic construct to support the development of rapid, low-cost and easy composition of distributed applications even in heterogeneous environments" [1]. The most promising "service" introduced are switching paradigm from exclusive utilization of computer resources to the cooperation of many computer resources so that every stakeholders can take part on serve and to be served with existing "service" technology.

Why it has to be called service? Basically the cloud has no ownership, it consist of many resources owned by many people and used by many people with no ownership way. It means every people can use any resources available, doesn't care if whether it free or proprietary "service". The "service" trend has produced new term in computing, "everything as a service". We can see all of the computer resources "as a service".

\subsection{Infrastructure as a service}

Prodan (2009) in his survey of cloud technology taxonomy said that term infrastructure as a service (IaaS) refers to the technology that "provides generic functionality for hosting and provisioning of access to raw computing infrastructure and its operating middleware software". IaaS can be seen as any physical infrastructure of information technology provided by some service providers which can be used to be utilized by any users without the need of give any investment on building such a technology [2].

Bhardwaj (2010) discussed many aspects of IaaS. A specific thing from Bhardwaj is, he seen the term IaaS as an evolution of traditional hosting infrastructure. The difference between IaaS and the traditional hosting is in the contract commitment of the time duration of use. The "service" term in the IaaS means, users can use its service on demand and just pay its service per its use [3]. Bhardwaj definition is still debatable on how we interpret ate the term "service" there. But, it's quite interesting how Bhardwaj give explanation about IaaS in his perspective.

Bhardwaj thinks that IaaS in another form of hosting with special and flexibility. The most benefit from this service is the flexibility of pricing, since the users only need to pay for the resources that they used. So that's why, this service has to be some components: utility computing service and billing model; automation of administrative tasks; dynamic scaling; desktop virtualization; policy-based services; and the most important thing, internet connectivity [3]. The IaaS model explained by Bhardwaj can be seen in the Figure 1.

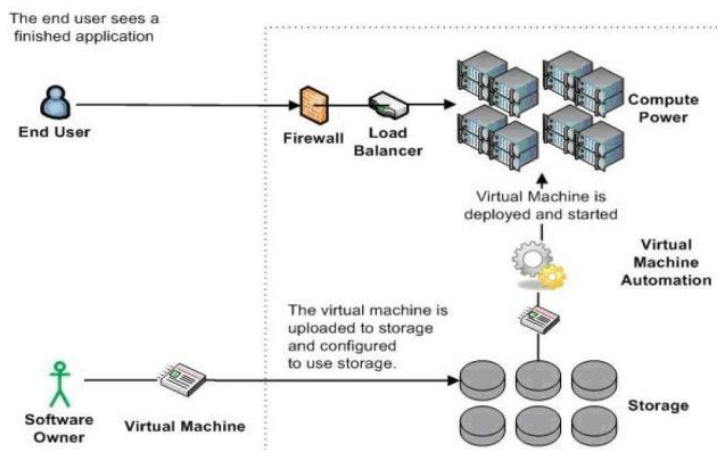

Fig 1. Infrastructure as a service model [3].

Another view of IaaS comes from Dawoud. He has similar perspective with Bhardwaj but in his paper, Dawoud give more stressed on a view that cloud as an IaaS, is different from the term "service oriented architecture" (SOA). This two term is kind of complementary thing, while SOA is set of principles and methodologies to facilitate the communication and integration of different kind programming languages and different platform of system developed, cloud and IaaS have focused on enabling massive computing services. Dawoud explanation about IaaS components also similar with Bhardwaj. IaaS have to include: service level agreement (SLA); utility computing; platform virtualization; network \& internet connectivity; and computer hardware as its basic components to provide the services [4].

We can say that Amazon Elastic Cloud (Amazon EC2) is one of the service technologies that can be seen as an IaaS. Amazon EC2 fits many aspects from Bhardwaj and Dawoud explanation.

\subsection{Platform as a service}

Lawton wrote nice article on platform as a service (PaaS). Lawton explain that "PaaS model 
is a novel approach for software suppliers who want to focus primarily on the software development cycle and the monetization of new applications, thus bypassing the investment on and maintenance of the underlying infrastructure/services for application design, development, testing, deployment and hosting." Basically, the term PaaS refers to software development framework that supports "as a service" point of view [5].

Tian gives slightly different but supporting perspective on PaaS. Tian explained PaaS in the term of virtualization environment. He describes a platform in PaaS as an environment (virtually) for software developers that can be accessed and viewed as a service. In the rest of the paper, he explained technical aspect about how to build the virtual environment as a platform of service needed in cloud virtual laboratory [6].

Another researcher, Zhou, proposed specific PaaS model for enterprise cloud technology. Zhou thinks when enterprise system adopted PaaS, it has to address specific requirements that challenges the environment of enterprise system include: cloud status (private or hybrid) to implement; openness cloud to the external environment; industry specific standards; diversity of business model and roles; time to deliver solutions; various applications and user types; users characteristic \& requirements; and business agility [7].

PaaS can be seen as a framework that suits on "as a service" technology, gives support for anyone who wants to develop software that utilize the cloud environments. Term PaaS totally different with IaaS. Though we can say that "platform" can be seen as hardware of computing resources, it resembles as framework of certain environment. While "infrastructure" is more as physical things. Google has began this initiatives by releasing Google App Engine that open wide chance for any developers to use Google cloud resources for their software.

\subsection{Software as a service}

Compared to IaaS and PaaS, the term software as a service (SaaS) is more popular. According to [8], "SaaS lets organizations create new software applications dynamically to meet rapidly changing business needs. As its construction becomes automated, however, software understanding will become more difficult." Gold describes 'what the future software has to be' in his explanation, as the business evolution, it needs dynamic changing software to align with. Another definition come up from [9], he states that "SaaS is a model of software deployment whereby a provider licenses an application to customers for use as a service on demand". This definition correlate this term with two "as a service" term discussed before (IaaS \& PaaS).

The big difference of traditional software with SaaS is the opposite view on software technology, software as a good or software as a service. Olsen describes this opposite paradigm, software as a service will have different approach on the life cycle and different engineering requirements than if it is treated as a good [10]. The traditional software engineering treated software as a good, though it quite different, software as a service engineering have to build based on traditional approach with some aligning process.

Benneth view on SaaS (at that time Benneth doesn't use term 'SaaS' but use term 'future software') is coming from the users and developers differences. Benneth thinks that traditional software is more supply-side, developers view. Although, there are user requirements capturing, supply paradigm on software development is quite dominant. The SaaS switch its paradigm into demand-side, users view. User can access this software whenever they demand. So, that's why, benneth characterized SaaS as follows: it has necessary and sufficient requirements; user's personalized; self-adapting; fine-grained; and transparent [11]. This view of Benneth is the initial researcher thinking of SaaS as a future generation of software.

Nowadays, many companies have already released their SaaS. The most popular clusters are social media software and the web-based multimedia types. The software gives users services, whether it free or pay. Facebook, Twitter, Wordpress, Blogspot, Youtube, and Plurk are some examples of SaaS.

\subsection{Data as a service}

This term maybe is not popular as Saas, IaaS, and PaaS. Truong describes the DaaS as technology of data service that "allow consumers to create, store and manage their own data according to their specific data models and offer functionalities to allow their consumers to acquire or provide data under the service model." [12]. Well, it is rather confusing what does the DaaS means but another paper somehow gives a missing link in understanding DaaS. Aulbach in [13] discussed about multi-tenant database that can support SaaS, he compare five database model that have a potential to become good model of DaaS. Although, Aulbach experiment conclude that there is no suitable database model yet to support Daas, from this paper we can clearly see that discussion is about storage model of data. 
Truong address some problems that probably have to be considered in DaaS include: quality of data; data source; usage of data; data governance; quality of service; and service context [12]. All of the problems shown that data integrity is the most important aspect on DaaS. This all reasonable because DaaS provide service to the users in the form of data, storage, and its manipulation.

\section{Welcoming IS as a service}

"Information system is a set of interrelated elements or components that collect (input), manipulate (process), and disseminate (output) data and information and provide a feedback mechanism to meet an objective" [14].

From the definition of information system (IS), we can see that information technology infrastructure, platform or framework, software; data are parts of information system. All those computer parts must be aligned with the business process of the organization that will develop or adopt the information system. When every components of IS are going towards the service oriented technology, obviously the IS will also come forward into that directions.

Besides, the information technology evolutions that come towards that trend, business evolution also come up with the service paradigm. Traditional service paradigm in business is outsourcing trend. Many businesses outsource their non core business to other party. Well, in the future it doesn't close any chance if the information technology including information system will be outsourced as well. The term service oriented technology has a similar interpretation with the outsourcing.

\subsection{Why it has to be "as a service"}

As it explained before, the future business process will come up with the idea that non core businesses are better to be outsourced. Although this idea is quite debatable on effectiveness and efficiency, fact that IS investment are needed very large amount of money, utilizing IS as a service is one of the solutions.

Gold in [8] also discussing the chance of the IS. The first reason is open marketplace for service. If we see this reason from the vendor's view, the chance for survive in the IT business by providing IS services is quite high. The marketplace still open for any player that provide IS service for the company which doesn't want to invest too much resources in implementing IS which is not become their core business (kind of like supporting system).

The second reason is dynamic provision in response to changing request. Rapid change in business process and information technology development, positively will give big cost in changing the IS. IS as a service will dynamically adaptive with those environments. From the view of customers, rapid change of IS environment will not harm their business, as of service oriented characteristic is on demand service, the customers can easily change their vendor if one of the vendor used can't adapt the rapid change.

The last sentence related to the third reason, potential for one-time execution followed by unbinding. The customers can have lower expenses on maintenance the IS since they just used the service whenever they need and after need, they just can easily unbinding from its services. Of course this kind of service doesn't include the routines business activity.

The fourth reason is service supply network. The IS as a service will connect many organization with different resources. They can interchange their resources; serve other organization with their resources and to be served with other organization resources. Free or proprietary is not the problem. The main issue is they can get whatever services though they don't own its technology.

The last reason is delivery transparency. One of the cloud characteristics is transparent. The users can't see what is behind the services. When each organization interchanges their resources, no one can see each other background. With this aspect, the competitiveness of companies will still exist and the nature of the business doesn't change at all.

\subsection{IS as a service in a nutshell}

Basically, the key concepts and principles of IS as a service similar and can be addressed from IaaS, PaaS, SaaS, and DaaS point of view. What will be discussed in this section are two main aspect which is IS as a service environment characteristics and IS as a service generic process model.

\subsubsection{Characteristics}

The characteristics of IS as a service derived from service oriented discussion from [15]. Six characteristics are: loosely coupled, whole system are divided into several parts which have low dependencies each other; implementation neutrality, which are not depending on several technology or programming language; flexible configurability, as of users need easiness and dynamic changing; persistence, although it have on-demand characteristics system have to wake at long term to make sure that the service given is still relevant for the customers; granularity, dividing part of system have to be fine-grained; 
and team, rather than framing centrally, IS as a service have to make it computational decentralized.

\subsubsection{Generic process model}

One most important thing when discussing IS is generic process model or IS development life cycle. As it has been discussed by [10] that IS as a service must have been treated differently from traditional view that treat IS as a good. The generic process model for IS as a service derived from [16] which discussed the generic process model for SOC.

Generic process model for IS as a service consists of four phases: analyzing business process, defining service composition, acquiring service components, and running services systems. The first phase is to analyze the set of available service requirements, and to identify core business processes which are expected by service consumers. The second phase is to define a service composition for each business process identified. The next phase is to search for right service components and bind them together to fulfill the service composition [16]. And, the last phase is to run the service composition. The phases can be seen clearly from the Figure 2 .

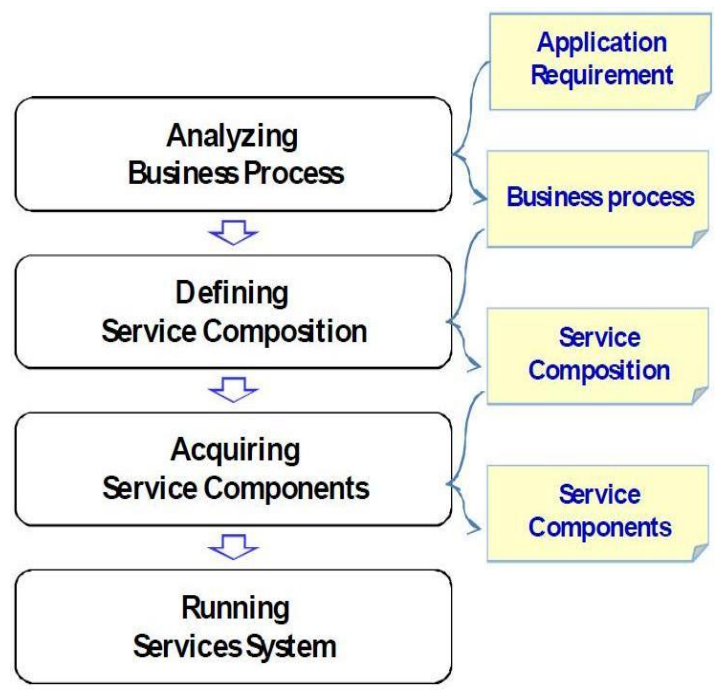

Fig 2. Generic Process Model for IS as a Service [16].

The key artifacts on this generic process model are business process layer, service composition layer, service interface layer, and component layer. The business process represents a cohesive unit of the service that will be provided, it clearly independent from any platform or technology that will be used. It consists of several activities and workflow to identify the business process. The service composition layer is a design model for a business process that consists of unit service and service collaboration. Any activity in business process layer correspondence to one of the service composition layer unit service.

Service interface layer are middleware that connect conceptual logical view of the system to the technical aspect in the component layer. Service interface consists of unit service interface that related to each unit service in the higher level. The component implementation is the basic engine of the system. The illustration can be seen in Figure 3.

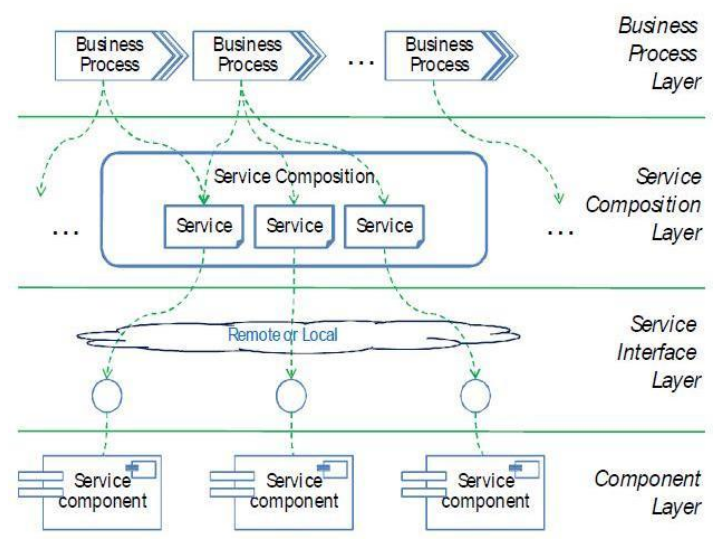

Fig 3. Key artifact relationship [16]

\subsubsection{System design}

One of the main different between service paradigm and conventional paradigm of information system development is the view of developers to the products itself. Conventional paradigm view the IS product as a goods, it is clearly have different point of view with service paradigm. Here will be shown how the products being built from different paradigm. Figure 4 . Shows the differences between the conventional paradigm and the service paradigm.

Here, we will show one of the alternatives of database design with the service paradigm. [18] Introduced the database design for IS as a service paradigm. He proposed two different scenario of database system that will provide the storage services to any tenants that use their services. First scenario is multi-tenant with shared databases. This scenario provided multi schema with personalized features for tenants. Using this scenario, provider doesn't need to build several databases, they only have to customize their schemas so different tenant can have different schema based on their preference. Figure 5 . Shows the detail design for this kind of scenario. 


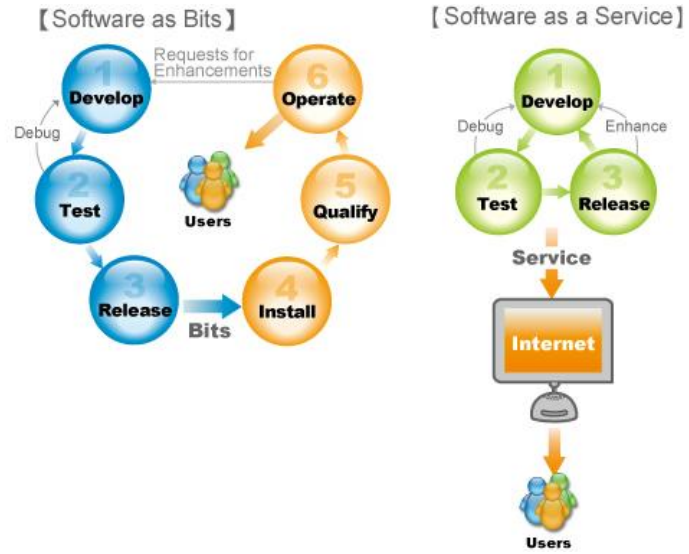

Fig 4. Different paradigm of development paradigm [17]

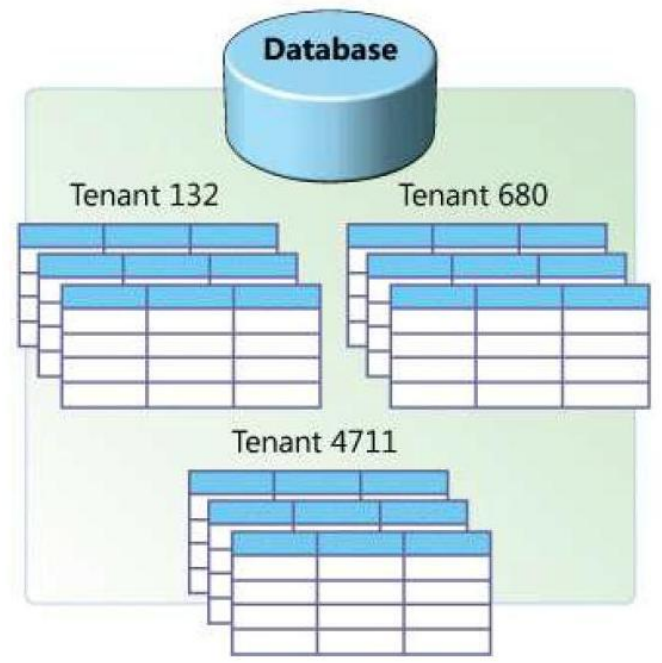

Fig 5. Multi-tenants shared database design [17]

Second scenario is multi-tenants with dedicated databases. Using this scenario, users can have their own dedicated database server. Dedicated server means dedicated resources; this is the advantages from the first scenario. Of course each scenario has different purpose, and not one of them have certain superiority, it should be different market of system that provided. Figure 6. Shows the detail design of multi-tenant dedicated database.

\section{Discussion}

The concept of IS as a service is somehow promising if we see the trend of cloud technology and service oriented computing that rise in current time. However, there are many things that have to be addressed before we say that IS as s service is the future technology and the new era of information system. One of the biggest opponents of this paradigm is Richard M. Stallman and the society of GNU and Free Software Foundation. For them, the basic idea of service is nonsense.
When the process, data, platform and software given to the other party as a service, it means the customers lost their freedom of ownership. Besides, several proprietary services will locked up the customers to make sure the customers are only using their technology.

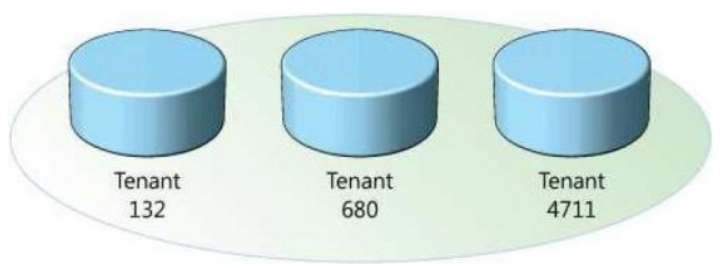

Fig 6. Multi-tenant dedicated database design [17]

In other perspectives, IS as a service will give more chance in IT market. The numbers of vendor providing many services will increase and of course it will trigger the economic add value in IT business. From the customer's view, IS as a service will give more efficiency and lower their cost of IT investment, or maybe none of IT investment they have to pay. They can easily pay the service they use and easily change the environment without any hesitation of legacy system left behind.

\section{Conclusion}

This paper has addressed the future trend of information system based on service or IS as a service. There are many to be found and still lot of problems to be solved. But, as information technology evolved, it is a must for the information system to be evolved in the same way.

\section{References}

[1] M.P. Papazoglou. "Service-Oriented Computing: concepts, characteristics, and directions," in Proceedings of the 4th IEEE International conference on web information systems engineering, pp. 3-12, 2003..

[2] R.Prodan and S.Ostermann. "A survey and taxonomy of infrastructure as a service and web hosting cloud providers, " in Proceeding of 10th IEEE/ACM International Conference on Grid Computing, pp. 17-25, 2009.

[3] S. Bhardwaj et.al. "Cloud Computing: A Study of Infrastructure as a service (IAAS), " International Journal of Engineering and Information Technology, vol. 2, no. 1, 2010. 
[4] W. Dawoud et.al. "Infrastructure as a service security: challenges and solution," in Proceeding of The 7th IEEE International Conference on Informatics and Systems (INFOS), pp. 1-8, 2010.

[5] G. Lawton. "Developing Software Online with Platform-as-a-Service Technology," IEEE Computer Magazines, vol. 41, no. 6, pp. 13-15, June, 2008.

[6] W. Tian et.al. "A Framework for Implementing and Managing Platform as a service in a virtual cloud computing laboratory, " in Proceeding of 2nd IEEE International Workshop on Education Technology and Computer Science, pp. 273-276, 2010.

[7] Y.C. Zhou et.al. "Business Process Centric Platform as a service Model and Technologies for Cloud Enabled Industry Solutions," in Proceeding of IEEE 3rd International Conference on Cloud Computing, pp. 534-537, 2010.

[8] N. Gold et.al. "Understanding ServiceOriented Software", IEEE Software, vol. 21, no. 2, pp. 71-77, 2004.

[9] M. Zhou et.al. "Services in the cloud computing era: a survey," in Proceeding of 4th IEEE International Universal Communication Symposium, pp. 40-46, 2010.

[10] E.R. Olsen. "Transitioning to software as a service: Realigning Software Engineering Practices with The New Business Model," in Proceeding of IEEE International Conference on Service Operations and Logistics and Informatics, pp. 266-271, 2006.
[11] K. Benneth et.al. "Service-based Software: The Future of Flexibel Software, " in Proceeding of 7th IEEE Asia Pasific Software Engineering Conference, pp. 214-221, 2000.

[12] H.L. Truong et.al. "On Analyzing and Specifying Concerns for Data As a Service, " in Proceeding of IEEE Asia Pacific Services Computing Conference, pp. 87-94, 2009.

[13] S. Aulbach et.al. "A Comparison of Flexible Schemas for Software as a Service, " in Proceeding of 35th SIGMOID International Conference on Management of Data, 2009.

[14] Z.A. Hasibuan "Basic Concept of ISD, " Week 1 Lecture of Advanced Topics in information System, Faculty of Computer Science, Universitas Indonesia, 2011.

[15] M.N. Huhns et.al. "Service-oriented computing: key-concepts and principle," IEEE Internet Computing, vol. 9, no. 1, pp. 75-81, 2005.

[16] S.H. Chang et.al. "An approach for verification in service oriented computing, " in Proceeding of IEEE Congress on Services, pp. 575-582, 2008.

[17] Different paradigm of software development. [Online], Available: http://www.autoehub.com/eng/images/ File: solution4.jpg accessed 26 December 2011.

[18] F. Chong, G. Carraro, and R. Wolter. "Multi-Tenant Data Architecture". [Online], Available: http://msdn.microsoft.com/enus/library/aa479086.aspx accessed 26 December 2011. 